dimensional nature of such an experience, and draws attention to the need for professions involved in the care of patients to be seen to trust and value the contribution of others to the total care offered. This seemed to be one of the better accounts of the dimensions of health care with which social work might be involved.

\title{
Psychology and Psychiatry
}

\section{Jeffrey Garland}

Christie, A. B., 'Changing Patterns of Mental Illness in the Elderly', British Journal of Psychiatry, 1982, I 40, pp. I 54-159.

As the 'bulge' in the proportion of people over seventy-five continues to swell ominously over the next decade, we can expect to see many more such papers by consultants in psychogeriatrics, bemoaning with Dr Christie that 'the rising prevalence of dementia and the increasing survival of demented patients, is posing serious problems for the psychogeriatric services'. The problems from the patients' point of view aren't exactly trivial either, but the author, understandably, does not pause to consider this as he launches into this clearly-presented account of a thoughtprovoking study.

He describes a partial replication of the major investigation of prognosis of mental illness in old people reported from Graylingwell Hospital by Roth in $1955^{1}$ At the Crichton Royal from 1974 to 1976 all patients admitted to the psychogeriatric unit were followed up at six and twentyfour months following admission (as in the Graylingwell study). Unfortunately, due to differences in the lower age limit for admission and lack of two-year follow-up data for some of the Graylingwell patients, the original $45^{\circ}$ of Roth's patients are reduced to 143 for this comparison, which is with 265 of the 343 Crichton Royal admissions during the period under review. Christie gives us no way of guessing whether the rump of Roth's cohort is representative of the original $45^{\circ}$, and we can only hope that it is, in view of the many comparisons made here between the hospitals.

A key finding is that functional illness (affective psychosis and late paraphrenia) found relatively frequently at Graylingwell has given way at the Crichton Royal to dementia, not as a proportion of the patients admitted but in the number of beds employed for their care six and twenty-four months after their index admission (admission rates for the elderly with dementia have actually been falling recently as the prolonged survival of already admitted patients restricts the rate for new admissions). 


\section{Jeffrey Garland}

For example, at six months, of Graylingwell's thirty-two beds, seventeen were required for functional cases and fifteen for dementias; while of Crichton's twenty-nine beds, three were required for functional cases and twenty-six for dementias. At two years the same trends are broadly in evidence.

As Christie points out, at Crichton: 'In-patient work has undergone a radical change. Functional cases have been more than replaced by a dementing population who are surviving longer than their predecessors. The number of beds required at two years for these patients has increased four-fold, and despite the decline in the number of beds required for functional cases, the bed requirements per r oo admissions at two years has now risen from thirteen to eighteen, an overall increase of thirty-eight per cent. The death rate at two years has dropped by thirty-one per cent, the fall being more marked among dementias (from eighty-seven per cent to fifty-five per cent) than the functional group (forty-one per cent to twenty-four per cent).'

Some of the main reasons for these changes are clear. More effective use of phenothiazines and anti-depressants and the growth of community support services has made functional illness more manageable, while there has been little comparable progress to report in the management of dementia. Indeed, as Christie indicates, more efficient antibiotics are part of an improved spectrum of hospital physical care of demented patients, adding years to life if not life to years.

Are we already past the point of no return, having accepted that we must warehouse demented patients, giving them custodial supervision while they and we wait for their death, releasing beds for the same cycle? What can all our research insights offer in practical terms to improve the quality of life for this multiply deprived group of old people?

For those who support this journal, these questions demand to be answered.

\section{Oxford A.H.A.}

NOTE

I Roth, M. The natural history of mental disorder in old age. Journal of Mental Science, 1955, 101, 281-301. 